Uşak Üniversitesi Sosyal Bilimler Dergisi

$2014,7 / 2$

\title{
Üstbilişin Öğrenme, Öğretme ve Ölçme-Değerlendirme Açısından İncelenmesi*
}

\author{
Pinar KARAMAN** \\ Çavuş ŞAHIN ${ }^{* * * *}$ \\ Haydar DURUKAN ${ }^{* * * * *}$
}

\section{Özet}

$\mathrm{Bu}$ çalışmada, öğrencilerin öğrenmelerini destekleyen ve öz-yansıtmalı öğrenmlerine yardımcı olan üstbilişin önemi incelenmiştir. Araştırmada nitel araştırma yöntemlerinden biri olan doküman analizi kullanılmıştır. Doküman analizi yöntemi ile üstbiliş üzerine yapılan genel taramada, üstbiliş öğrenme, öğretme ve ölçme-değerlendirme açısından incelenmiştir. Araştırma sonuçları, üstbilişin öğrencilerin akademik başarılarını arttırdığını göstermektedir. Üstbilişsel öğretim aracıllğı ile öğrencilerin üstbiliş becerilerinde ve öğrenmelerinde gelişme sağlanabileceği görülmektedir. Ayrıca, üstbilişsel öğretim sırasında öğrenme odaklı ölçme-değerlendirmeyi kullanmak öğrencilerin üstbiliş seviyelerini geliştirebilmektedir (Jones, 2007). Dolayısıyla, öğrencilerin üstbiliş düzeylerini geliştirebilmek için öğrenmeodaklı ölçme-değerlendirme yaklaşımını kullanmak ve bunu yaygınlaştırmak çok önemlidir. Birçok araştırmacı, karmaşık yapıya sahip olan üstbiliş alanını ölçmenin oldukça zor olduğunu savunmaktadır. Bu nedenle, öğrencilerin üstbiliş alanları ile ilgili daha geçerli ve güvenilir bilgi toplayabilmek için onların yeterli zorlukta üstbilişsel aktiviteler ile etkileşim göstermeleri gerektiği önerilmektedir.

Anahtar Kelimeler: Üstbilişsel öğrenme, üstbilişsel öğretim, üstbiliş ve ölçme-değerlendirme

\section{An Exploration Of Metacognition With Respect To Teaching, Learning And Assessment}

\section{Abstract}

This study investigated the importance of metacognition that helps students' self-directed and self-reflective learning. With that purpose, document

\footnotetext{
* Bu çalışma ULEAD, Mayıs-Haziran, 2013 Ürgüp/Nevşehir Kongresinde tam metin bildiri olarak sunulmuştur.

${ }^{* *}$ Dr., pkaraman1626@gmail.com

*** Doç. Dr., Çanakkale Onsekiz Mart Üniversitesi, csahin25240@yahoo.com

**** Yard. Doç. Dr., Çanakkale Onsekiz Mart Üniversitesi, durukanh@yahoo.com.tr
} 
analysis method as one of the qualitative research methods was used in the study. In the document analysis, metacognition was researched in terms of learning, teaching and assessment. The literature review showed that metacognition can lead to promoting students' academic achivement. A myriad of studies indicated that metacognitive teaching plays an important role in students' metacognitive skills and learning. Besides, using learningoriented assessment methods during metacognitive teaching can enhance students' metagontion level (Jones, 2007). Therefore, in the course of teaching, using or expanding learning-oriented assessment methods is important for students' metacognitive development. Many reserchers agree that measuring metacognition is so difficult due to its complex nature. Therefore, in order to collect more valid and reliable evidence about students' metacognitive domain, the students should interact with metacognitive activities having adequate level of difficulty.

Keywords: Metacognitive learning, metacognitive teaching, metacognition and assessment

\section{Giriş}

Eğitimde artık öğrencilerin bilgiyi pasif olarak almasından çok bilgiye ulaşma, bilgiyi elde etme ve bu esnada zihinsel süreçleri yönetme ve üst seviyede zihinsel beceriler kazanma gibi özellikleri üzerine yoğunlaşma söz konusudur. Birçok çalışma tarafından öz-yönetimli (self-directed learning) ve öz-yansıtmalı öğrenmenin (self-reflective learning), öğrencilerin akademik ve bireysel gelişimleri üzerinde olumlu etki gösterdiği kanıtlanmıştır. Öğrenme kuramları ile ayrılmaz bir bağlantısı olan üstbiliş (metacognition) kavraminın ise (Veenman, Van Hout-Wolters ve Afflerbach, 2006), öğrenmeyi planlama, izleme, değerlendirme ve problem çözme açısından öz-yönetimli öğrenme (self-regulated learning) yapisına çok benzediği görülmektedir (Boekaerts, 1999). Bu bağlamda, son otuz yıldır eğitim psikologları tarafından öğrencilerin kendi öğrendiklerini kontrol etmelerini sağlayan ve öğrenmeyi destekleyen üstbilişin önemi üzerine vurgu yapılmaktadır. 1997 yılında Amerikan Psikoloji Birliği, son yüzyılda yapılan önemli araştırmalara dayalı olarak, biliş ve üstbilişin etkili öğrenme için önemli bir faktör olduğunu ortaya çıkarmıştır (Mok vd, 2006). Araştırmalar, üstbilişin sosyal öğrenme kuramında ve bireysel gelişimde hayati öneme sahip olduğuna işaret etmiştir. Üstbiliş yaşla birlikte ve uygun öğretim ile gelişebilmektedir. Ancak araştırmacılar, üstbilişsel becerilerin gelişimi üzerinde öğretimin etkisinin olgunlaşmaya göre daha fazla 
olduğunu ortaya çıkarmıştır (Gage ve Berliner, 1988). Uygun bir üstbilişsel öğretim, öğrencilerin öğrenme stratejilerine daha geniş açıdan bakmalarını sağlayarak öğrencilerin pratik zekalarını (practical intelligence) geliştirebilmektedir (Flavell, 1979). Farklı eğitim kademelerinde okuyan özyönetimli (self-directed) başarılı öğrenciler, kendi bilgilerini değerlendirebilmekte, kendi bilişsel süreçleri ve becerilerini sorgulayabilmektedir (Joseph, 2010). Üstbilişsel öğretim ile öğrenci kendi düşünceleri hakkında farkındalık kazanmış olmakta ve engellere maruz kalmadan zorluklarla mücadele ederek çalışmayı öğrenebilmektedir (Hoyt ve Sorensen, 2001; Peverly, Brobst ve Morris, 2002). Öğretim metotlarında ve materyallerinde üstbilişsel farkındalık öğretilerek stratejik öğrenciler yaratılabilmektedir (Jacobs, 2003). Öğrencilerin üstbilişsel farkındalıkları geliştirilerek öğrenme süreçlerinde daha etkili olması sağlanabilir (Jones, Farquhar ve Surry, 1995). Üstbilişsel farkındalık, öğrencilerin entellektüel olgunluk kazanmalarına yardımcı olmaktadır (Joseph, 2010). Ayrıca, üstbilişsel beceri ile akademik başarı arasında anlamlı bir ilişki olduğu görülmektedir (Case, Harris ve Graham, 1992; Deseote ve Roeyers, 2002). Dolayısıyla, üstbiliş ve üstbilişsel farkındalığın çocukların ve yetişkinlerin eğitiminde önemli bir yeri olduğu söylenebilir (Kramarski, Mevarech ve Arami, 2002; Mevarech, 1999; Schraw, 2009; Teong, 2002).

\section{Araştırmanın amacı}

$\mathrm{Bu}$ çalışma, üstbilişin eğitimdeki önemini ortaya çıkarmayı planlamaktadır. Bu doğrultuda, üstbiliş öğrenme, öğretim ve ölçmedeğerlendirme açısından detaylı olarak incelenmiştir. Çalışmanın alt amaçlarında şu sorulara cevap aranmıştır:

1. Üstbilişin öğrenmeye katkısı nedir?

2. Üstbilişsel öğretim nasıl gerçekleşir?

3. Öğrenme-odaklı ölçme ve değerlendirmenin üstbiliş gelişimine katkıları nedir?

4. Üstbiliş nasıl ölçülmektedir?

\section{Yöntem}

\section{Araştırma Deseni}

Araştırmada nitel araştırma yöntemlerinden biri olan doküman analizi kullanılmıştır (Karasar, 1995). Doküman analizi, öncelikli olarak yapılan çalışmaların ne içerdiği üzerine odaklanır ve çalışmalardan sentez oluşturarak okuyucuya anlamlı mesajlar iletir (Given, 2008). Doküman analizi ışığında yapılan araştırmalar iki amaç doğrultusunda yapılabilmektedir: genel tarama ve içerik çözümlemesi (Bakırcı ve Çepni, 
2012). Bu çalışmada, doküman analizi yöntemlerinden biri olan genel tarama ya da literatür taraması kullanılmıştır. Üstbiliş üzerine yapılan literatür taramasında, üstbiliş öğrenme-öğretme ve ölçme-değerlendirme açısından detaylı olarak incelenmiştir. Literatür taraması sonucu ortaya çıkan sonuçlar kuramsal açıdan tartışılmıştır.

\section{Veri Toplama süreci}

$\mathrm{Bu}$ çalışmada, üstbiliş öğrenme-öğretme ve ölçme-değerlendirme alanında literatür taraması yapılarak incelenmiştir. Genel tarama sonucu, özellikle ölçme-değerlendirme boyutunda üsbiliş alanı üzerine yapılan çalışmaların sınırlı olduğu söylenebilir.

\section{Bulgular}

Bu bölüm, üstbiliş kavramı, üstbilişsel öğrenme, üstbilişsel öğretim, ölçme-değerlendirmenin üstbilişsel gelişim için önemi ve üstbilişin nasıl ölçüldüğü hakkındaki konuları içermektedir.

\section{Üstbiliș}

Üstbiliş̧, bireyin öğrenme süreci sırasındaki bilişsel aktiviteler ile ilgili bilgi ve düzenlemeleri içerir (Flavell, 1979). Üstbiliş, bireyin üstbilişsel süreçleri ve stratejileri hakkındaki farkındalığı olarak tanımlanır (Flavell, Green ve Flavell, 1995). Bireyin öz-yansitıcı (self-reflective) olma özelliği ile ilişkili olan üstbiliş ile bireyin öğrenme süreci sırasında nasıl düşündüğü ve anladığı, bilgiyi nasıl özümsediği ve anladığına dikkat çekilir (Jones, 2007). Böylelikle, üstbiliş bireyin tam anlamıyla öğrenmesi ve anlaması için düşünme mekanizmasını geliştirmesine yardımcı olur. Vygotsky (1962)'nin de vurguladığ gibi, öğrenci kendi düşünme süreçlerinin bilincinde olduğu zaman nasıl öğrendiği üzerine kontrol kazanır. Yıllardır yaygın olarak kullandığımız üstbiliş kavramı ile ilişkili birkaç terim ortaya çıkmıştır: üstbilişsel inançlar, üstbilişsel farkındalık, üstbilişsel deneyimler, üstbilişsel bilgi, bilmeyi hissetmek, öğrenmeyi yargılamak, zihin kuramı, üstbellek (metamemory), üstbilişsel beceriler, üst-düzey beceriler, meta-bileşenler, anlayarak izleme, öğrenme stratejileri, buluşsal (heuristic) stratejiler ve özdüzenleme (self-regulation) (Veenman vd., 2006). Veenman ve arkadaşları, üstbiliş kavramında, üstbilişsel bilgi ve beceriler ayrı olarak ele alır. Kendi öğrenme sürecimizi yansıtan üstbilişsel bilginin doğru ya da yanlış olabileceğini ve bu öz-bilginin (self-knowledge) değişimlere kapalı olabileceğini ifade etmişlerdir. Üstbilişsel becerilerin ise, geri-bildirim 
mekanizmasına sahip olduğunu ve dönüşümlere açık olduğunu vurgulamışlardır.

Üstbiliş, iki önemli bileşenden oluşur: üstbilişsel bilgi (knowledge) ve üstbilişsel kontrol (Jacobs ve Paris, 1987; Schraw ve Moshman, 1995; Lai, 2011). Üstbilişsel bilgi, öğrenen bireyin bilgisidir ve bireyin performansını etkileyebilecek faktörleri içerir. Üstbilişsel bilgi aynı zamanda, öğrenen bireyin stratejilerini içerip, bu bilgiyi ne zaman ve neden kullanacağını yönlendiren bilgidir. Diğer bir ifade ile üstbilişsel bilgi, bireyin bilişsel becerilerini, üstbilişsel stratejileri, durumlara göre ne yapılabileceğini bilmesi olarak tanımlanır (Özsoy ve Günindi, 2011). Krathwohl'da revize edilmiş taksonomisinde dört genel bilgi kategorisini tanımlamıştır: olgusal (factual), kavramsal (conceptual), işlemsel (procedural) ve üstbilişsel bilgi. Olgusal, kavramsal ve işlemsel bilgi kategorileri orjinal taksonomide yer almakta olup üstbilişsel bilgi kategorisi revize edilmiş modelde yeni bir kategoridir (Pintrich, 2002). Üstbilişsel kontrol ise, öğrenen bireyin kendi bilişini kontrol etmesidir. Bu sırada birey, etkinlikleri planlar, anladıkları ya da kavradıklarının bilincinde olur, yaptığ 1 bir işte performans sarf eder ve bu süreç sırasında uygulanan stratejileri ve etkililiği takip ederek değerlendirme yapar. Çalışmalarda genellikle tahmin, planlama, izleme ve değerlendirme olmak üzere dört önemli üstbilişsel beceri üzerine yoğunlaşılmıştır (Desoete ve Roeyers, 2002; Lucangeli ve Cornoldi, 1997; Özsoy, 2010; Özsoy ve Günindi, 2011). Öğrenci üstbilişsel beceri olarak tahmin yaparken, öğrenme sürecini hedefleyerek sürecin alacağ zaman ve sonuçları hakkında düşünmeye yönlenir. Birey tahminlerine dayalı olarak beklentilerini düzenler. Dolayısyla tahmin etme becerisi, öğrencilerin belirli bir durum ya da iş karşısında karşılaşacakları zorluk ya da kolaylıkları önceden görebilmelerini sağlayarak buna göre çalışmalarında düzenleme yapma imkanı sağlar (Desoete ve Roeyers, 2002). İkinci beceri olarak planlama becerisi, bireyin uygun kaynakları ve stratejileri kullanabilme becerisidir (Schraw, 2009). İzleme becerisi ise, bireyin bilişsel bir performansı ya da işi sırasında ne anladığının ve nasıl bir performans gösterdiğinin farkında olmasıdır. Birey, öğrenme sürecinin hedeflerine bağlı olarak sonuçlarını sorgulayarak değerlendirme yapabilmesi de önemli üstbilişsel bir beceridir.

Üstbilişin iki ana bileşeni olan üstbilişsel bilgi ve üstbilişsel kontrol ya da düzenlenme arasındaki etkileşim sonucu, üstbilişsel deneyimler oluşur. Birey kazandığı üstbilişsel deneyimler sonucu bilişsel bilgilerini arttırır, değiştirir veya düzenleyebilir (Aktürk ve Şahin, 2011).

Üstbiliş gelişimi, üstbellek ve üstbilişsel bilgi gelişimi ile başlamakta ve hayat boyu devam etmektedir (Alexander, Carr ve Schwanenflugel, 1995). 
Temel seviyede üstbilişsel bilgi ve beceriler çoğunlukla okulöncesi dönemde başlamakta ve formal eğitim aldıkça gelişmektedir (Veenman vd., 2006). Üstbilişsel farkındalığın yaklaşık 5 yaşında geliştiği, üstbilişsel becerinin ise 11 yaşına kadar gelişmediği belirtilmiştir (Veenman ve Spaans, 2005). Bilişsel kuramlar, çocukların genellikle 11 yaş civarında, düşüncelerinin performanslarını etkileyebileceğinin farkına varabildiklerini açıklamaktadır (Alexander, Carr ve Schwanenflugel, 1995). Ayrıca, çocuğun 11 yaş civarında, bilinçli ve yanstıcı üst seviyede düşünme (meta-thinking) özelliklerinin geliştiği söylenmektedir (Veenman and Spaans, 2005).

\section{Üstbilişsel Öğretim}

Öğretmenlerin güçlü ve etkili bir öğretim gerçekleştirebilmelerinin altında yatan en önemli faktörlerden biri öğrencilerin üstbilişsel farkındalıklarını geliştirebilmeleridir. Üstbilişsel gelişim karmaşık bir süreçtir. Araştırmalar sonucu, başarılı bir üstbilişsel öğretim için üç temel kural ortaya atılmıştır: (1) üstbilişsel öğretimin içerik ile bağlantı kurularak verilmesi, (2) öğrencileri üstbilişsel aktivitelerin kullanışlılığı hakkında bilgilendirerek daha fazla efor harcamalarını sağlamak, (3) başarılı üstbilişsel aktiviteler için uzun süreli bir eğitim sağlanması. Öğretmenlerin öğrencilerde üstbilişsel gelişimi sağlayabilmeleri için üç önemli öğretim becerisine sahip olmaları gerekir (Williams, 2006). Birincisi, öğretmenin öğrenciye yoğun düşünebileceği işler ya da görevler verebilmesi. İkincisi, öğrencilerin korkmadan, karşılıklı saygı içerisinde düşünme ve muhakeme yapabildiği, araştırma yapmaya teşvik edilen bir sınıf ortamı sağlayabilmesi. Üçüncü öğretim becerisi ise, öğrencilere öğrendikleri ile ilgili düşüncelerini açıklayabilmeleri için zaman vermek. Üstbilişsel gelişim sürecinde merkezi rol oynayan öğretmen, öğrencileri öğrenme sırasında nasıl ve neden gibi sorulara düşünerek cevap verebilmesi için cesaretlendirir (Jones, 2007). Ancak yapılan araştırmalar, öğretmenlerin üstbiliş hakkında çok az bilgiye sahip olduklarını göstermektedir (Veenman, Kok ve Kuilenburg, 2001; Zohar, 1999). Bu nedenle öğretmenlerin üstbilişsel öğretimle ilgili eğitim almaları çok önemlidir. Öğretmenlerin üstbilişsel öğretim sırasında ne öğreteceği ve nasıl öğreteceği, öğrencilerin bireysel durumları göz önüne alarak yapması gerekir (Veenman vd., 2006). Veenman ve arkadaşları, öğretmenlerin sınıflarında üstbiliş aktiviteleri uygulayabilmeleri için öğretim materyalleri ihtiyaçlarının karşılanmasının da gerekli olduğunu vurgulamiştır. 
Üstbilişsel öğretim, geniş bir öğrenci aralığının üstbilişsel gelişimlerini sağlayabilmekte ve öğrenmelerini geliştirebilmektedir (Veenman, Elshout ve Busato, 1994). Fakat Pressley (2000), üstbilişsel öğretimin daha çok zayıf öğrencilerle ilişki gösterdiğini vurgulamıştır. Diğer taraftan, birçok öğrencinin belirli bir ölçüde ailesinden, akranlarından ve özellikle de öğretmenlerinden üstbilişsel bilgi ve becerileri alabildiği halde, çoğunlukla üstbilişsel yeterlilik gösteremedikleri görülmektedir (Veenman vd., 2006).

\section{Üstbiliş ve Ölçme-Değerlendirme}

Eğitimde artık öğrenme kazanımlarını ölçmek için summatif değerlendirme yanında öğrenme-öğretme süreci hakkında bilgi veren formatif değerlendirme de bir gereklilik haline gelmiştir. Formatif değerlendirme ile öğretmenler, tartışma ortamı sağlayarak öğrencilerin düşündürücü sorular ile meşgul olmalarını sağlar, akran ve öz değerlendirme, gözlemler, quizler, portfolyolar gibi uyguladıkları çeşitli etkinlikler aracılığı ile öğrenimin hızlanmasını sağlarlar (Şahin ve Karaman, 2013). Formatif değerlendirme yaklaşımı, beş önemli özelliği ile öğrenmeyi geliştirir (Black ve William, 2003): (1) öğrencilere etkili geri-dönüt sağlamak, (2) öğrencilerin kendi öğrenmelerinde aktif rol almalarını sağlamak, (3) ölçme-değerlendirme sonuçlarına göre öğretimi düzenlemek, (4) öğrencilerin öz-saygı (self-esteem) ve motivasyonlarını geliştirmek, (5) öğrencilerin kendilerini değerlendirerek nasıl geliştiklerini anlama fırsatı vermek. Öğrencilerin kendilerini değerlendirerek gelişimlerini izleme fırsatı sağlayan formatif değerlendirme, örtük olarak öğrencilerin üstbilişsel farkındalıklarının gelişimine de yardımcı olmaktadır (Jones, 2007). Sadler (1998), formatif değerlendirmenin iki önemli faktöre bağlı olduğunu vurgulamıştır. Birincisi, öğrencilerin öğrenme hedefi ile şu andaki seviyesi arasındaki aralığı anlamaları gerekir. İkinci olarak ise, öğrencilerin bu aralığı kapatmaları gerekir. Her ne kadar öğretmen bu süreci harekete geçirip öğrenciye rehberlik etse de, öğrenmenin öğrenciler tarafından gerçekleşmesi gerekir (Black vd., 2003). Diğer bir ifade ile, öğrenme-öğretme sürecinde öğrenciler aktif rol oynamalıdır. Öğrencilerin öğrenme, öğretme ve ölçmedeğerlendirme sırasında aktif rol alması, üstbilişsel farkındalık gelişimi için oldukça önemlidir (Jones, 2007). Öğrencinin etkin rol oynadığı ve öğrenme için geri bildirim sağlanan öğrenme-odaklı ölçme-değerlendirme yaklaşımı, öğrencinin daha derin ve etkili öğrenmesini sağlar (Black ve Wiliam, 1998). Dolayısıyla, öğrenme odaklı ölçme-değerlendirme öğrencinin üstbilişsel gelişimini sağlayabilir. Örneğin, öğrenme-odaklı ölçme-değerlendirme yöntemlerinden biri olan öz-değerlendirme (self-assessment) aracilığı ile 
öğrenci öğrenme süreci sırasında yansıma yapar ve geri-dönüt oluşturur. Böylelikle, öz-değerlendirme öğrencilerin öğrendiklerini daha derin anlamasını, kullandıkları öğretim stratejilerini geliştirmelerini sağlayarak üstbilişsel gelişimlerine ve gelecek derslerdeki faaliyetlerine katkıda bulunur (Mok vd., 2006).

Üstbilişin ölçülmesi ise birçok sebepten dolayı oldukça zordur: (1) üstbiliş karmaşık bir yapıdır, (2) üstbiliş doğrudan gözlenemez, (3) üstbiliş hem sözel yeteneğin hem de bellek kapasitesinin karışımı olabilir, (4) varolan ölçümler daha dar alana odaklanma ve öğrenmeden uzak olma eğilimindedir (Lai, 2011). Bu nedenle, öğretmenlerin üstbilişsel bilgiyi ölçerken kullanacakları ölçme-değerlendirme uygulamaları formal olmaktan daha çok informal olma eğiliminde olacaktır (Pintrich, 2002). Pintrich, öğretmenlerin informal yolla üstbilişsel bilgiyi ölçerken genellikle öğrencilerin bilişlerini ve ne öğrendiklerini dinleyerek yaptıklarını öne sürmüştür. Öğretmenlerin görüşmeler sonucu, hem sınıflarındaki genel üstbilişsel seviyesini hem de içerik bilgisini ölçmüş olacaklarını belirtmiştir. Pintrich, bu çeşit informal değerlendirmenin öğrencilerin hem içerik bilgi kazanımı (olgusal, kavramsal veya işlemsel) hem de üstbilişsel bilgi kazanımına yardımcı olarak öğretimi düzenleyebileceğini vurgulamıştır. Üstbilişsel bilgiyi ölçerken kullanılan informal tekniklerin yanında anket, görüşme (interview) gibi formal değerlendirme tekniklerin de daha fazla kullanılması gerekmektedir (Pintrich, Wolters ve Baxter, 2000) . Flavel (1987) yakın zaman içerisinde, üstbilişsel deneyimleri değerlendirmek için uygun metotların gelişeceğine inansa da, şu ana kadar sunulan metotların bazı güçlü ve zayıf yönlerinin olduğu görülmektedir (Panaoura ve Philippou, 2005). Üstbilişi ölçmek için anket, görüşme (interview), sesli düşünme analizleri, gözlemler, online bilgisayar log dosyası kaydı, göz hareketi kaydı gibi birçok yöntem kullanılmıştır. Fakat bu yöntemlerin hepsinin bazı güçlü ve zayıf yönlerinin olduğu görülmektedir (Veenman vd., 2006). Örneğin, görüşme (interview) sırasında oluşturulan tüm sözel raporlar birçok sinırlılı̆ga sebep olabilmektedir (Miles, Blum, Staats ve Dean, 2003). Çünkü öğrenciler görüşme sırasında kendi bilişsel süreçleri ile ilgili sorulara cevap verirken tam olarak kendilerini yansitamayabilmektedir. Anketler büyük gruplara kolaylıkla uygulanabilirken, sesli düşünme analizleri bireysel ölçme ve değerlendirmeyi gerektirir (Veenman vd., 2006). Üstbilişsel aktiviteler ölçülürken çoğunlukla kullanılan anketlerde ölçülen skorlar performans sırasında oluşan gerçek davranışsal ölçümleri çok az yansitabilmektedir (Veenman, Prins ve Verheij, 2003). Bundan dolayı, 
üstbilişsel bilgi veya beceriyi başarılı bir şekilde ölçmek için uygun ölçmedeğerlendirme metodunu belirlemek gerekir (Veenman vd., 2006).

Diğer taraftan, üstbilişi ölçerken genellikle belirli bir alan ölçülmektedir (domain-specific) (Veenman ve Spaans, 2005). Örneğin, üstbilişsel bir alan olarak matematiksel problem çözme, öğrenme çıktılarını tahmin ederek önemli bir rol oynayabilir (Desoete ve Veenman, 2006; Fuchs vd., 2010). Öğrenci, matematiksel problem çözerken, analiz yapar, yapacağ1 görevi keşfeder, bir çözüm planı oluşturur, planı uygular ve cevabı doğrular (Schoenfeld, 1992). Jacobse ve Harskamp (2012) ise, üstbilişsel süreçlerin offline (bağlantısız) veya on-line (bağlantılı) öğrenme yoluyla ölçülebileceğini önermiştir. Veenman vd. (2006), on-line öğrenme sürecinde ölçülen üstbiliş yoluyla öğrenme için açıklanan değişkenin yaklaşık \%37'lik kısmının açıklanabildiğini ortaya çıkarmıştır. En çok kullanılan off-line ölçümler ise, öğrencilerin kendi üstbilişlerini anlatmalarını sağlayan anketlerdir (Jacobse ve Harskamp, 2012). Bunlara örnek olarak Üstbilişsel Farkındalık Envanteri (Schraw ve Dennison, 1994), Öğrenme ve Çalışma Stratejileri Envanteri (Weinstein, Zimmermann ve Palmer, 1988) verilebilir. Bununla birlikte, offline ölçümler öğrencinin devam eden üstbilişsel davranışlarını ölçmeyip sadece öğrenme için gösterdiği performans öncesi ve sonrasına odaklanmaktadır (Greene ve Azevedo, 2010). Bu nedenle, üstbilişi ölçmek için kullanılabilecek off-line ölçümler bazı problemlere sebep olabilmektedir (Jacobse ve Harskamp, 2012):

1. Öğrencinin üstbilişini açıklayan anketler, bir öğrenme işi gerçekleştirmeden toplanmaktadır. Bundan dolayı öğrenci, uzun süreli hafızasından yararlanarak daha erken süreçlere ve performansa ulaşmak zorundadır.

2. Öğrencilerin anket sorularına cevapları ve yorumları durumlara göre zihinlerinde oluşturdukları çerçeveye göre farklılıklaşmaktadır (McNamara, 2011).

3. Öğrencilerin hemen cevaplandırması beklenilen anketler (selfreport), öğrencilerin davranışlarını yanlış ifade etmelerine sebep olabilmektedir (Cromley ve Azevedo, 2011).

Sonuç itibariyle, üstbilişi açıklamak için kullanılan anketlerin (selfreport), tam anlamıyla doğru sonuçlar verdiğini söylemek güçtür. Üstbilişi ölçmek için anket (self-report) kullanan yaklaşık 21 çalışma sonucunda da, üstbiliş yoluyla öğrenmeyi açıklayan değişkenin \% 3'ü geçmediği ortaya çıkmıştır (Veenman ve Van Hout-Wolters, 2002). On-line öğrenme süreci ile 
ilgili üstbilişsel bilgi toplamanın yollarından biri ise, öğrencinin plan tasarlama, not alma gibi gözlenebilir olaylarda performans göstermesidir (Winne ve Perry, 2000). Matematiksel problem çözmede en önemli bilişsel hareket, öğrencinin bir plan ya da taslak oluşturmasıdır (Jacobse ve Harskamp, 2012). Öğrencilere bir plan oluşturmayı öğretmek, problem çözerken nasıl düşündüklerinin daha net anlaşılmasına yardımcı olmaktadır (Van Essen ve Hamaker, 1990). Yeterli zorlukta verilen problemler ile öğrencilerin üstbilişsel aktiviteler ile etkileşime girmesi sağlanacaktır.

\section{Sonuç ve Öneriler}

Üstbiliş özetle, düşünme hakkında düşünme olarak tanımlanan çok boyutlu bir beceridir (Lai, 2011). Araştırmalar üstbiliş becerisi yüksek olan öğrencilerin akademik başarılarının arttığını göstermektedir. Üstbilişsel bilgi ve beceriler eğitim kademesi ilerledikçe ve uygun öğretim ile gelişebilmektedir (Veenman vd., 2006). Üstbilişsel öğretim ile geniş bir öğrenci aralığında üstbiliş ve öğrenme gelişimi sağlanabilmektedir (Veenman vd., 1994). Bundan dolayı üstbiliş, öğrencilerin eğitiminde önemli bir rol oynar.

Öğrencilerin üstbilişsel gelişiminde merkezi rol oynayan öğretmenlerin ise uygun öğretim stratejilerini uygulayabilmeleri için üstbiliş hakkında yeterli bilgiye sahip olmaları gerekir. Bu nedenle, öğretmenlerin üstbiliş alanında eğitim almaları çok önemlidir.

Diğer taraftan, etkili bir üstbilişsel öğretim sırasında uygulanan öğrenme-odaklı ölçme ve değerlendirme yaklaşımı da, öğrencilerin üstbilişsel farkındalık gelişimlerini sağlayabilmektedir (Jones, 2007). Bu ölçme ve değerlendirme yaklaşımı ile öğrencilerin etkin rol oynamaları, öğrenme süreci sırasında kendi gelişimlerini izleme ve değerlendirme firsatı sağlayabilmeleri, yansıma yapabilmeleri, geri-dönüt oluşturabimeleri sayesinde üstbilişsel farkındalıkları gelişebilmektedir. Öğrenme-odaklı ölçme ve değerlendirme yaklaşımının üstbilişsel gelişime önemli katkılarından dolayı (Mok vd., 2006), öğretim sürecinde daha çok kullanılması ve yaygınlaştırılması gerekmektedir.

Birçok araştırmacı, üstbilişin üzerinde çalışılması gereken önemli bir yapı olduğunu fakat ölçülmesinin ise oldukça zor olduğuna işaret etmektedir (Schraw, 2000). Karmaşık bir yapıya sahip olan üstbilişin ölçülmesinde genellikle informal ölçme-değerlendirme uygulamalarına eğilim daha fazladır (Pintrich, 2002). Üstbilişi ölçmek için informal değerlendirme tekniklerin yanında uygun ve etkili formal değerlendirme 
tekniklerini de kullanmak gerekir. Ayrıca, araştırmacılar tarafından üstbilişi ölçerken kullanılan off-line ölçümler birçok açıdan eleştirilmektedir. Anket (self-report) soruları ile öğrencinin performans öncesi ve sonrasına odaklanan off-line ölçümler, öğrencinin devam eden üstbilişsel davranışlarını tam anlamıla ölçememektedir. Öğrencinin üstbilişsel davranışlarını ölçerken gözlenebilir olaylarda plan tasarlama, not alma gibi performansı ile on-line ölçümler yapılabilmektedir. Araştırmalar, on-line öğrenme sürecinde ölçülen üstbiliş yoluyla öğrenmeyi açıklayan değişkenin (Veenman vd., 2006), off-line öğrenme sürecinde ölçülen üstbiliş yoluyla öğrenmeyi açıklanan değişkene göre (Veenman ve Van Hout-Wolters, 2002) oldukça yüksek olduğunu göstermektedir. Dolayısıyla, öğrencilerin üstbilişsel alanı hakkında daha geçerli ve güvenilir bilgi toplayabilmek için öğrencinin yeterli zorlukta bir üstbilişsel aktivite ile etkileşime girmesi ve performans göstermesi önerilmektedir. Sonuç itibariyle, üsbilişsel alan ile ilgili etkili ve anlamlı ölçme-değerlendirme etkinliklerini kullanmak ve geliştirmek başarılı üstbilişsel öğrenme ve öğretimin gerçekleşmesine katkıda bulunacaktır.

\section{Kaynakça}

Aktürk, A.O. ve Şahin, İ. (2011). Üstbiliş ve bilgisayar öğretimi, Ahmet Keleşoğlu Eğitim Fakültesi Dergisi, (31), 383-407.

Alexander, J. M., Carr, M. and Schwanenflugel, P. J. (1995). Development of metacognition in gifted children: Directions for future research, Developmental Review, 15, 1-37.

Bakırcı, H. ve Çepni, S. (2012) Fen ve Teknoloji Öğretimi için yeni bir model: Ortak bilgi yapılandırma modeli X. Ulusal Fen Bilimleri ve Matematik Eğitimi Kongresi, TR, Haziran.

Black, P., Harrison, C., Lee, C., Marshall, B. \& Wiliam, D. (2003) Assessment for learning: Putting it into practice, Oxford University Press, Oxford, United Kingdom.

Black, P. and Wiliam, D. (1998). Assessment and classroom learning, Assessment in Education, 5(1), 7-74.

Boekaerts, M. (1999). Self-regulated learning: Where we are today.International Journal of Educational Research, 31, 445-457.

Case, L. P., Harris, K. R. and Graham, S. (1992). Improving the mathematical problem solving of students with learning disabilities: Self-regulated strategy development. The Journal of Special Education, 26,1-19. 
Cromley, J. and Azevedo, R. (2011). Measuring strategy use in context with multiple-choice items.Metacog-nition and Learning, 6, 155-177.

Desoete, A. and Roeyers, H. (2002). Off-line Metacognition - A Domainspecific Retardation in Young Children with Learning Disabilities. Learning Disability Quarterly. 25, 123-139.

Desoete, A., and Veenman, M. V. J. (2006). Metacognition in mathematics: Critical issues on nature, theory, assessment and treatment., In A. Desoete and M. V. J. Veenman (Eds.), Metacognition in mathematics education, New York: Nova Science Publishers, Inc,1-10.

Flavell, J. H. (1979). Metacognition and cognitive monitoring: A new area of cognitive-developmental inquiry. American Psychologist, 34(10), 906-911.

Flavell, J. H. (1987). Speculation about the nature and development of metacognition. In F. Weinert \& R. Kluwe (Eds.), Metacognition, motivation, and understanding, Hillsdale, NJ: Lawrence Erlbaum, $21-29$.

Flavell, J., Green, F., and Flavell, E.(1995). Young children's knowledge about thinking (Monographs for the Society for Researching Child Development No. 60.1), Chicago, University of Chicago Press.

Fuchs, L. S., Zumeta, R. O., Schumacher, R. F., Powell, S. R., Seethaler, P. M., Hamlett, C. L., and Fuchs, D. (2010). The effects of schemabroadening instruction on second graders' word-problem performance and their ability to represent word problems with algebraic equations: a randomized control study, The Elementary School Journal, 110 440-463.

Gage, N. L. and Berliner, D. C. (1988). Educational Psychology, (4th Ed.). Boston, MA: Houghton Mifflin Company.

Given, L. (2008). The Sage Encyclopedia of Qualitative Research Methods, ISBN 978-1-4129-4163-1,Thousand Oaks, CA:Sage, California.

Greene, J. A., and Azevedo, R. (2010). The measurement of learners' selfregulated cognitive and metacognitive processes while using computer-based learning environments.Educational Psychologist, 45, 203-209. 
Hoyt, J. E. and Sorensen, C. T. (2001). High school preparation, placement testing, and college remediation. Journal of Developmental Education, 25,26-33.

Jacobs, L. (2003). Stacking the deck for literacy learning. Princi-pal Leadership, 4(3), 57-60.

Jacobs, J. and Paris, S. (1987). Children's Metacognition about Reading: Issues in Definition, Measurement, and Instruction. Educational Psychologist, 22(3-4), 255-278.

Jacobse, A. E. and Harskamp, E.G. (2012). Towards efficient measurement of metacognition in mathematical problem solving, Metacognition Learning, 7:133-149.

Jones, D. (2007). Speaking, listening, planning and assessing: the teacher's role in developing metacognitive awareness, Early Child Development and Care, 177:6-7,569-579.

Jones, M. G., Farquhar, J. D. and Surry, D. W. (1995). Using Metacognitive Theories to Design User Interfacesfor Computer-Based Learning. Educational Technology, 35, 12-22.

Joseph, N. (2010). Metacognition Needed: Teaching Middle and High School Students to Develop Strategic Learning Skills. Preventing School Failure, Vol. 54, No. 2.

Karasar, N. (1995). Araştırmalarda Rapor Hazırlama, 10. baskı, Nobel Yayın Dağıtım Ltd. Şti., Ankara.

Kramarski, B., Mavarech, Z. R., and Arami, M. (2002) The Effects of Metacognitive Instruction on Solving Mathematical Authentic Tasks, Educational Studies in Mathematics, 49, 225-250.

Lai, E. R. (2011). Metacognition: A Literature Review, Research Report, Pearson, Always learning.

Lucangeli, D. and Cornoldi, C. (1997). Mathematics and metacognition: What is the nature of relationship? Mathematical Cognition, 3, 121139.

McNamara, D. S. (2011). Measuring deep, reflective comprehension and learning strategies: challenges and successes. Metacognition and Learning, 6, 195-203. 
Mevarech, Z. R. (1999) Effects of Metacognitive Training Embedded in Cooperative Settings on Mathematical Problem Solving, The Journal of Educational Research, 92,195-205.

Miles, D., Blum, T., Staats, W. and Dean, D. (2003) Experiences with the metacognitive skills inventory, 33rd ASEE/IEEE Frontiers in Education Conference. (on line). Available:http://fie.engrng.pitt.edu/fie2003/papers/1184.pdf.

Mok, M. C. C., Lung, C. L., Cheng, D. P. W., Cheung, R. H. P. and Ng, M. L. (2006). Self-assessment in higher education: experience in using a metacognitive approach in five case studies, Assessment \& Evaluation in Higher Education, 31(4), pp. 415-433.

Özsoy, G. (2010) An investigation of relationship between metacognition and mathematics achievement. Asia Pacific Education Review.

Özsoy, G. ve Günindi, Y. (2011). Okulöncesi öğretmen adaylarının üstbilişsel farkındalık düzeyleri, Elementary Education Online, 10(2), 430-440.

Panaoura A. and Philippou, G. (2005).The measurement of young pupils'metacognitive ability in mathematics: The case of selfrepresentation and self evaluation, CERME 4, Spain, February.

Peverly, S. T., Brobst, K. and Morris, K. S (2002). The contribution of reading comprehension ability and metacognitive control to the development of studying in adolescence. Journal of Research in Reading, 25, 203-216.

Pintrich, P.R. (2002). The Role of Metacognitive Knowledge in Learning, Teaching, and Assessing, Theory into Practice, 41(4).

Pintrich, P.R., Wolters, C. and Baxter, G. (2000). Assessing metacognition and self-regulated learning, In G. Schraw and J. Impara (Eds.), Issues in the measurement of metacognition. Lin-coln, NE: Buros Institute of Mental Measurements, 43-97.

Pressley, M. (2000). Development of grounded theories of complex cognitive processing: Exhaustive within and between study analyses of thinking-aloud data. In G. Schraw, \& J. C. Impara (Eds.), Issues in the measurement of metacognition (pp. 262-296). Lincoln, NE: Buros Institute of Mental Measurements. 
Schoenfeld, A. H. (1992). Learning to think mathematically: Problem solving, metacognition, and sense making in mathematics. In D. A. Grouws (Ed.), Handbook of research on mathematics teaching, New York: McMilan Publishing, 224-270.

Schraw, G. (2000). Issues in the measurement of metacognition. Lincoln NE: Buros Institute of Mental Mesaurements and Erlbaum Associates.

Schraw, G. (2009). A conceptual analysis of five measures of metacognitive monitoring. Metacognition and Learning, 4, 33-45.

Schraw, G., and Dennison, R. S. (1994). Assessing metacognitive awareness.Contemporary Educational Psychology, 19, 460-475.

Schraw, G., and Moshman, D.(1995). Metacognitive theories, Educational Psychology Review, 7(4) 351-371.

Şahin, Ç. ve Karaman, P. (2013). Sınıf öğretmeni adaylarının ölçme ve değerlendirmeye ilişkin inançları. Hacettepe Üniversitesi Eğitim Fakültesi Dergisi [Hacettepe University Journal of Education], 28(2), 394-407.

Teong, S.K. (2002). The Effect of Metacognitive Training on Mathematical Word-Problem Solving. Journal of Computer Assisted Learning, 19, $46-45$.

Van Essen, G. and Hamaker, C. (1990). Using self-generated drawings to solve arithmetic word problems.The Journal of Educational Research, $83,301-312$.

Veenman, M. V. J., Elshout, J. J., and Busato, V. V. (1994) Metacognitive mediation in learning with computer-based simulations.Computers in Human Behavior, 10, 93-106.

Veenman, M. V. J., Kok, R., and Kuilenburg, J. (2001). Intelligence and metacognitive skillfulness in secondary education. In F. Oser \& U. Baets (Eds.), 9th European Conference on Learning and Instruction, Abstract Volume (pp. 166), Aachen: Mainz.

Veenman, M. V. J., Prins, F. J. and Verheij, J.(2003). Learning styles: Selfreports versus thinking-aloud measures. British Journal of Educational Psychology, 73, 357-372.

Veenman, M. V. J., and Spaans, M. A. (2005). Relation between intellectual and metacognitive skills: age and task differences, Learning and Individual Differences, 15, 159-176. 
Veenman, M. V. J. and Van Hout-Wolters, B. (2002). Het meten van metacognitieve vaardigheden [Measuring metacognitive skills]. In F. Daems, R. Rymenans, \& G. Rogiest (Eds.),Onderwijsonderzoek in Nederland en Vlaanderen. Proceedings 29e ORD 2002(pp. 102-103). Wilrijk: Universiteit van Antwerpen.

Veenman, M.V.C., Van Hout-Wolters, B. H. A. M., and Afflerbach, P. (2006), Metacognition and learning: conceptual and methodological considerations, Metacognition Learning, (1): 3-14.

Vygotsky (1962)., L. S., Thought and language, Cambridge, MA, MIT Press.

Weinstein, C. E., Zimmermann, S. A. and Palmer, D. R. (1988). Assessing learning strategies: The design and development of the LASSI. In C. E. Weinstein, E. T. Goetz, P. A. Alexander, C. E. Weinstein, E. T. Goetz, and P. A. Alexander (Eds.),Learning and study strategies: Issues in assessment, instruction, and evalu-ation(pp. 25-40). San Diego: Academic.

Williams, M. (2006). Letting talents shine: developing oracy with gifted and talented pupils, in: D. Jones \& P. Hodson (Eds) Unlocking speaking and listening, London, David Fulton.

Winne, P. H., and Perry, N. E. 2000). Measuring self-regulated learning. In M. Boekaerts, P. R. Pintrich, M. Zeidner, M. Boekaerts, P. R. Pintrich, \& M. Zeidner (Eds.) ,Handbook of self-regulation(pp. 531-566). San Diego: Academic.

Zohar, A. (1999). Teachers' metacognitive knowledge and the instruction of higher order thinking, Teaching and Teacher Education, 15, 413-429. 